\title{
Effects of NOTCH1 signaling inhibitor $\gamma$-secretase inhibitor II on growth of cancer stem cells
}

\author{
XIAODONG DING $^{1}$, CHANGQING DING $^{1}$, FEI WANG $^{2}$, WENSHUAI DENG $^{1}$, \\ MINGMING YU ${ }^{3}$, QINGHAI MENG ${ }^{1}$ and PENG SUN ${ }^{1}$
}

\author{
${ }^{1}$ Department of Neurosurgery, The Affiliated Hospital of Qingdao University, Qingdao, Shandong 266000; \\ ${ }^{2}$ Department of Neurosurgery, The Affiliated Hospital of Weifang Medical University, Weifang, Shandong 261031; \\ ${ }^{3}$ Department of Radiology, The Affiliated Hospital of Qingdao University, Qingdao, Shandong 266000, P.R. China
}

Received April 10, 2016; Accepted February 12, 2018

DOI: $10.3892 / \mathrm{ol} .2018 .9377$

\begin{abstract}
The present study aimed to observe the effect of the Notch1 signaling inhibitor $\gamma$-secretase inhibitor II (GSI II) on the growth and differentiation of tumor cells. The tumor cell line U87 was grown in serum-free media, and cell growth was evaluated using immunofluorescence. Single-cell wall-adherent growing conditions were prepared, GSI II was added, and the differentiation and growth of single tumor cells was evaluated. Immunofluorescence demonstrated positive results for the expression of Nestin and cluster of differentiation 133. The cell proliferation rate was reduced following the addition of GSI II $(\mathrm{P}<0.05)$. GSI II may significantly inhibit the proliferation and differentiation of U87 tumor stem cells.
\end{abstract}

\section{Introduction}

A defining characteristic of malignant brain tumors is their invasive growth and easy recurrence $(1,2)$, and therefore more effective treatment modalities are urgently required. A previous study revealed the existence of tumor stem cells (TSCs), which have the same functions as neural stem cells inside tumor cells including the ability to self-proliferate (3). There are a number of similarities between TSCs and neural stem cells that suggest the origin of TSCs (4), a variety of solid tumors, including brain tumors (5) and expression of numerous similar proteins (6). The discovery of TSCs has provided novel options for the treatment of brain tumors (7), including therapies targeting specific signaling pathways and transcription factors, and niche therapies targeting cancer stem cells $(8,9)$. TSCs serve major roles inside tumor tissues, acting

Correspondence to: Dr Xiaodong Ding or Dr Changqing Ding, Department of Neurosurgery, The Affiliated Hospital of Qingdao University, 1677 Wutaishanlu, Qingdao, Shandong 266000, P.R. China E-mail: xiaodongdingcn@126.com

E-mail: zhiqiangzheng@yeah.net

Key words: stem cells, brain tumor, Notch1, $\gamma$-secretase inhibitor II as a source for the proliferation and differentiation of tumors. Even in the presence of regulatory factors, TSCs continue to proliferate and differentiate; additionally, the next generation of cells retains the characteristics of the precursors. These characteristics include an unlimited proliferation ability, which promotes the rapid formation of tumor bodies as well as rapid reoccurrence following surgery, radiotherapy, and chemotherapy (10).

Nestin, a class VI intermediate filament protein, was originally detected in neural stem cells during development, and has been shown to be expressed in the transformed cells of various human malignancies (11). It is hypothesized to contribute to the aggressive behavior of these cells and facilitate tumor growth (12).

Cluster of differentiation (CD) 133 is one of the most commonly used markers of cancer stem cells (CSCs), which are characterized by their ability for self-renewal and tumorigenicity (13). Over-expression of CD133 is associated with solid cancers, many studies have correlated the overexpression of CD133 with survival, recurrence, metastasis or therapy resistance (14).

TSCs can regulate the conduction pathways involved in cell proliferation and differentiation; these pathways include, Notch (15), Wnt, sonic hedgehog (SHH), and Bmi-1 (16), which have important roles in regulating the growth of neural stem cells. A previous study has demonstrated the important roles of Wnt and the SHH signaling conduction pathways in regulating the proliferation of neural stem cells (17). When tissues are damaged, the self-protective roles of the Wnt and SHH signaling conduction pathways are activated to repair the damaged tissues, after which the corresponding pathways are disrupted through strict regulation. However, when certain genes, including casein kinase 1 epsilon (18) and sil (19), are mutated, the Wnt and SHH pathways can become abnormally activated, enabling cells to undergo unlimited proliferation and differentiation. The blocking of differentiation and maturation can induce tumors and abnormalities in the Wnt and SHH pathways can lead to glioblastoma (20); however, one study has identified that signal transduction pathway inhibitors can shrink tumors in mice until they have disappeared and induce rapid cell apoptosis of medulloblastoma in vitro (21). 
The Notch signaling pathway has been conserved throughout evolution and is involved in cell growth, proliferation, and differentiation. It not only serves important roles in cell fate during organ development, but also can be reactivated in disease states, participating in cell apoptosis, regeneration, and differentiation through cross-talk with other signaling pathways, which can affect the occurrence and development of various diseases $(22,23)$. However, few studies have examined these issues, and understanding the activities of these pathways is important for the development of novel cancer therapeutics.

The Notch signaling pathway is associated with tumorigenesis, and $\gamma$-secretase inhibitor II (GSI II) factor inhibits the activation of Notch1, which is a member of the Notch signaling pathway (24). In the present study, TSCs from the human brain tumor cell line U87 were identified, and then added GSI II to the human brain glioma cell line U87 for co-culture to observe the growth of TSCs.

\section{Materials and methods}

Materials. The cell culture medium contained Dulbecco's modified Eagles medium combined with Ham's F-12 nutrient mixture (DMEM/F12, Sigma Aldrich; Merck KGaA, Darmstadt, Germany) and 10\% fetal bovine serum (FBS; Wuhan Boster Biological Technology, Ltd., Wuhan, China). Additives included 2\% B27, $2 \% \mathrm{~N} 2$, epidermal growth factor $20 \mathrm{mg} / \mathrm{l}^{-1}$, and basic fibroblast growth factor $20 \mathrm{mg} / \mathrm{l}^{-1}$ (Wuhan Boster Biological Technology, Ltd.). Antibodies included rabbit anti-human Nestin antibody (cat. no. n5413; 1:100; Sigma-Aldrich; Merck KGaA), mouse anti-human CD133 antibody (cat. no. o43490; 1:500; Bioworld Technology, Inc., St. Louis Park, MN, USA), Cy3-labeled goat anti-mouse antibody (cat. no. BA103; 1:100; Wuhan Boster Biological Technology, Ltd.), fluorescein isothiocyanate (FITC)-labeled goat anti-rabbit antibody (cat. no. BA1105; 1:50; Wuhan Boster Biological Technology, Ltd.), and rabbit anti-human glial fibrillary acidic protein antibody (GFAP; cat. no. PAB18435; 1:500; Abnova, Tapei, Taiwan). Other materials included the tumor cell line U87 (U-87 MG ATCC ${ }^{\circledR}$ HTB14 $^{\mathrm{TM}}$; cat. no. CBP60299; Nanjing Ke Bai Biological Technology Co., Ltd., Nanjing, China), $0.01 \%$ poly-lysine, $0.25 \%$ trypsin, GSI II (Sigma-Aldrich, Merck KGaA), and Triton-X100 (Sigma-Aldrich, Merck KGaA).

Culture of TSCs. The tumor cell line U87 $\left(2 \times 10^{6}\right)$ was added to the culture media (DMEM/F12) of neural stem cells and cultured in a humidified incubator at $37^{\circ} \mathrm{C}$ with $5 \% \mathrm{CO}_{2}$. The media was intermittently exchanged (2-3 days) for 2-week culture period until spherical TSCs were observed, and immunofluorescence was performed for identification.

Immunofluorescence. TSCs $\left(1 \times 10^{5}\right)$ were seeded onto slides with polylysine pretreatment, $1 \mathrm{ml}$ of $10 \%$ acetone was added, and the slides were placed at $-20^{\circ} \mathrm{C}$ for $10 \mathrm{~min}$. Next, the slices were soaked with $0.1 \%$ Triton-X100 at room temperature for $1 \mathrm{~h}$, gently rinsed and soaked in 5\% goat serum (Wuhan Boster Biological Technology, Ltd.) at $20^{\circ} \mathrm{C}$ for $1 \mathrm{~h}$. The CD133 and Nestin antibodies were added to different groups of slides labeled Group A (CD133) and B (Nestin), and then incubated at $4^{\circ} \mathrm{C}$ for $24 \mathrm{~h}$. Next, $1 \mathrm{ml} 1 \%$ Cy3-labeled goat anti-mouse antibody was added to group A and $1 \mathrm{ml} 1 \%$ FITC-labeled goat anti-rabbit antibody was added to group B. Following an incubation at room temperature overnight, the slices were mounted with glycerol and cell staining was observed under a fluorescence microscope (magnification, x200). To the control group, neural stem cell culture medium was added to replace the CD133 and Nestin antibodies; the other steps were identical to those described previously.

Differentiation induction of TSCs. Cultured TSCs were transferred into $10 \%$ FBS-containing 24-well culture plates, and cultured at $37^{\circ} \mathrm{C}$ for $\sim 10$ days to observe their growth. When the TSCs clusters appeared as differentiated wall-adherent cells after $\sim 10$ days, immunofluorescence was performed to identify the cells; the primary antibody was changed to GFAP, and the secondary antibody was FITC, and the remaining steps were conducted as described previously.

Impact of GSI II on TSC growth. Cultured U87 cells were gently dispersed using a pipette and the concentration was adjusted to $10^{5}$ cells $/ \mathrm{ml}$ with $10 \%$ FBS. Next, $2 \mathrm{ml}$ cell suspension was added to each well of 6-well culture plates (the bottom of each plate had been evenly coated with $0.01 \%$ poly-lysine); culture was conducted in a humidified incubator at $37^{\circ} \mathrm{C}$ with $5 \% \mathrm{CO}_{2}$ for 2 days until the cells had completely adhered to the walls, after which the culture solution was removed. Stem cell culture medium $(2 \mathrm{ml})$ was added and the four plates were labeled A1, A2, B1 and B2. Next, 0.01 MPBS was added to A1 and A2 as the control group, and GSI II (0.2 $\mu \mathrm{g}$ per well) was added to $\mathrm{B} 1$ and B2 to observe changes in growth and the number of cell clusters in each culture plate was recorded. After a 20-day culture in the previously described culture conditions, the culture plates were directly stained as previously described.

Statistical analysis. The number of Nestin-positive cell clusters was recorded and SPSS 10.0 (SPSS, Inc., Chicago, IL, USA) was used to perform an analysis of variance followed by Fisher's least significant difference to compare the differences between different groups.

\section{Results}

Cells differentiated from U87 cells. The U87 cells were extracted and cultured in neural stem cell culture medium; after 2 days, wall-adherent cells began to grow in a cluster shape. After 4 days, the cell clusters gradually increased in volume and began to appear spherical in shape (Fig. 1). The spherical cells were re-dispersed and seeded into neural stem cell culture medium. Several days later, spherical cell structures had reformed.

Positive staining under a fluorescence microscope. Fluorescence microscopy revealed that the cell clusters in groups A and B exhibited red (Fig. 2) and green fluorescence, (Fig. 3), indicating that the CD133 and Nestin antigens were located inside the cells. The cell clusters were then placed into FBS medium for 10-day culture. Some cell clusters became wall-adherent again and presented a spindle shape; the cells also showed a high proliferation rate (Fig. 4). The wall-adherent cells, which were differentiated near the adjacent cell clusters, gradually exhibited cord-like connections (Fig. 5). The 


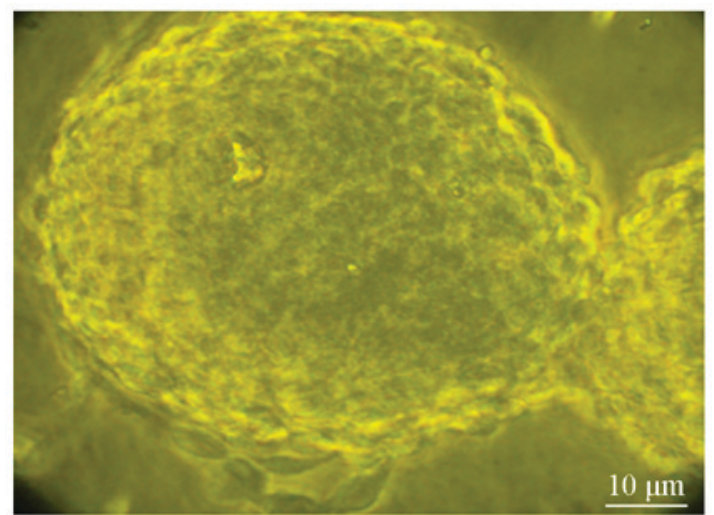

Figure 1. Cell ball after 10-day culture (magnification, x400).

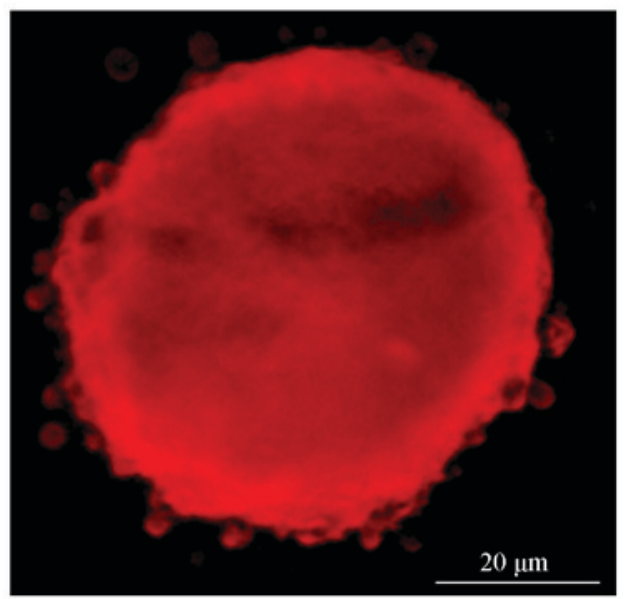

Figure 2. Cell ball with positive cluster of differentiation 133 staining via fluorescence microscopy (magnification, x200).

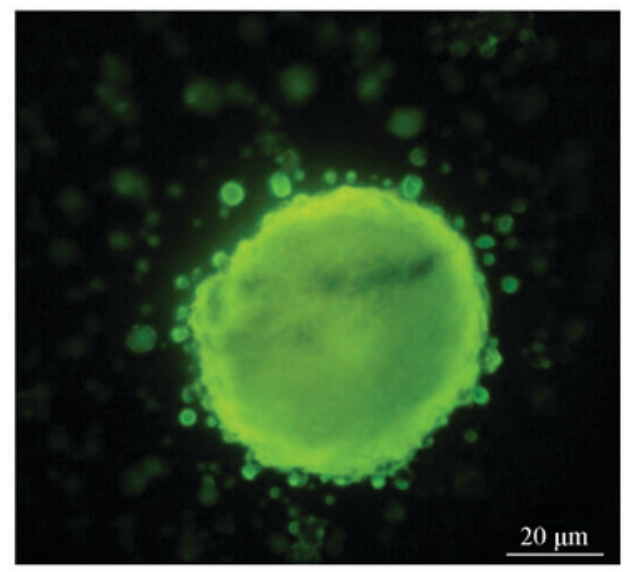

Figure 3. Performance of positive Nestin staining in fluorescence microscopy (magnification, x200).

differentiated cells were positive for GFAP staining (Fig. 6) and showed the same characteristics as glial cells.

Comparison of TSC growth rates between the 2 groups. The proliferation rates of cells in groups B1 and B2, which were incubated with GSI II, were significantly lower than those in the control groups A1 and A2 $(\mathrm{P}<0.01$, Table I). Single stem

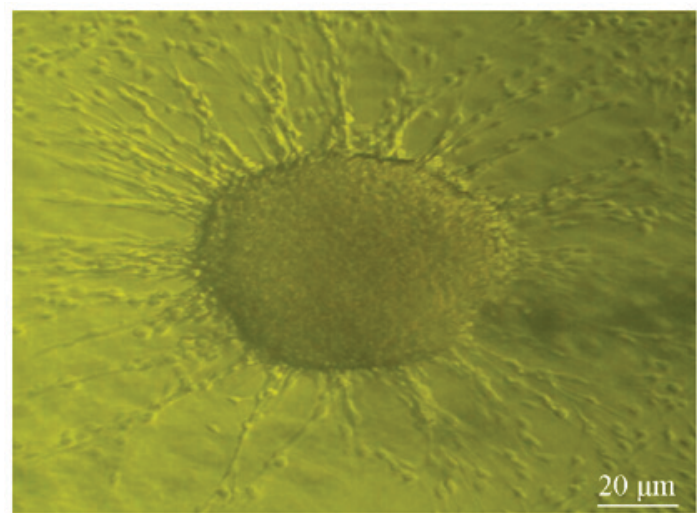

Figure 4. Differentiated wall-adherent tumor cells (magnification, x200).

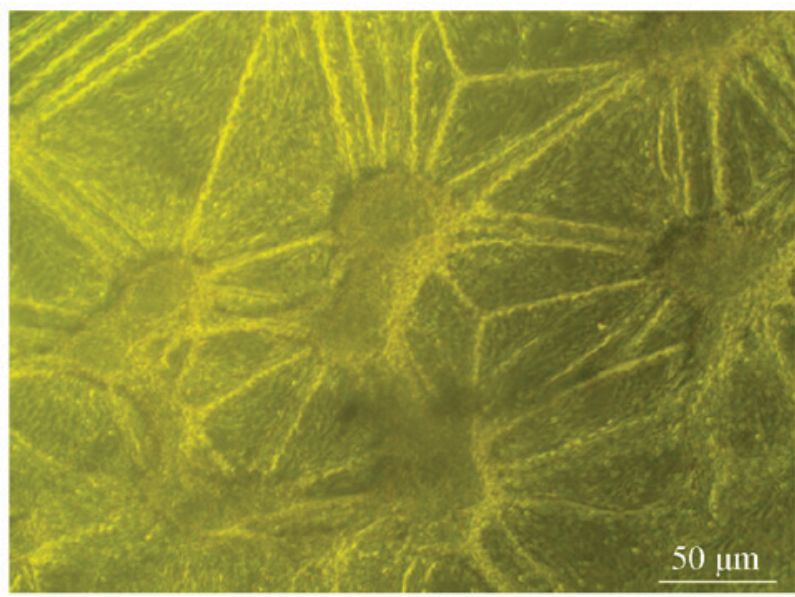

Figure 5. The differentiated cells exhibited cord-like connection (magnification, $\mathrm{x} 200$ ).

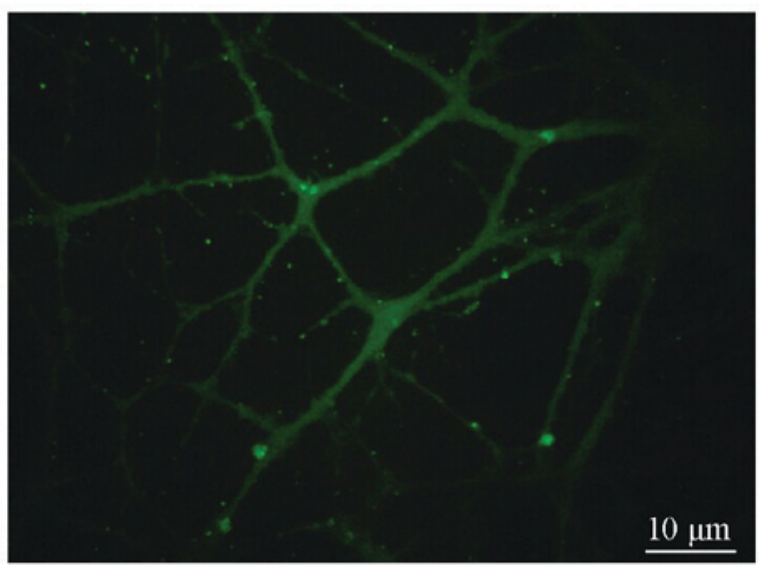

Figure 6 . The differentiated cells exhibited positive GFAP staining using fluorescence microscopy (magnification, x400).

cell clusters were positive for Nestin staining (Fig. 7), which confirmed the cells were tumor stem cells.

\section{Discussion}

Brain tumors have been suggested to originate from glial cells containing gene mutations that undergo differentiation 
Table I. The numbers of Nestin-positive cell clusters of the 2 groups.

\begin{tabular}{|c|c|c|c|c|c|c|c|c|c|c|c|c|c|c|c|c|c|c|c|c|}
\hline \multirow{2}{*}{$\begin{array}{l}\text { Group } \\
\text { Control group } \\
(\mathrm{A} 1+\mathrm{A} 2)\end{array}$} & \multicolumn{17}{|c|}{ Numbers of Nestin-positive cell clusters } & \multirow{2}{*}{$\frac{\text { mean } \pm \text { SD }}{11.78 \pm 2.96}$} & \multirow{2}{*}{$\frac{\mathrm{t}}{2.83}$} & \multirow{2}{*}{$\begin{array}{l}\text { P-value } \\
<0.05\end{array}$} \\
\hline & 13 & 12 & 13 & 10 & $14 \quad 12$ & 16 & 9 & 14 & 12 & 6 & 14 & 16 & 8 & 11 & 10 & 15 & 7 & & & \\
\hline $\begin{array}{l}\text { Experimental group } \\
(\mathrm{B} 1+\mathrm{B} 2)\end{array}$ & 11 & 10 & 9 & 10 & 1210 & 7 & 11 & 13 & 9 & 11 & 11 & 7 & 9 & 6 & 8 & 6 & ? & $9.39 \pm 2.96$ & & \\
\hline
\end{tabular}

$\mathrm{SD}$, standard deviation; $\mathrm{t}$, the statistical value.

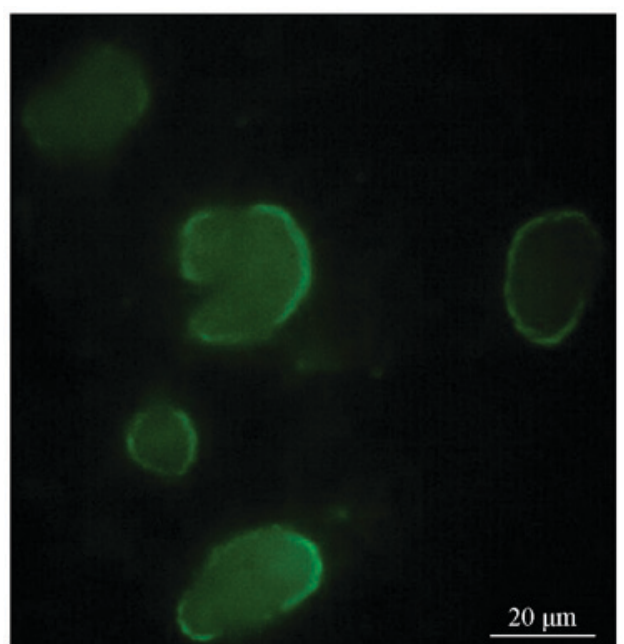

Figure 7. Nestin-positive cell cluster form in single-well culture using fluorescence microscopy (magnification, $\mathrm{x} 400$ ).

and maturation (25). The study of Hu et al (26) suggested that TSCs are present inside tumor tissues and that these cells can proliferate and differentiate into tumor cells. The study of Alamgeer et al (27) extracted and cultured tumor cells from lung and breast cancer and found TSCs showed differentiation ability. Fong et al (28) cultured spherical TSCs from mouse TSCs and found that both TSC types could grow in a suspension in culture media and retained the ability to differentiate into tumor cells after several passages. In the study of Lucarelli et al (29) tumor tissues were extracted from high-degree malignant tumors and the cell clusters that exhibited a similar growth state as stem cells were cultured. These previous studies only indirectly revealed the existence of TSCs, as no specific antigens were available for TSCs. At present, there are two principal markers that can be used for this purpose, including CD133, which is a transmembrane protein specific to neural stem cells and the majority of previous studies have used CD133 in order to identify glioma stem cells $(28,29)$. CD133 is highly expressed in glioma cells, and the ratio of CD133+ cells in glioma was demonstrated to be associated with the pathological type and prognosis (30). The other antigen used is against Nestin, a cytoskeletal protein that supports neural stem cells and is specific to neural stem cells (31). The U87 cell line was used in the present study, after several passages, neural stem cells were mixed with U87 cells, and these cells were used for the immunofluorescent identification of cell clusters as TSCs.
TSCs can proliferate and differentiate into tumor cells, and if the intermediate link is blocked, tumor growth can be inhibited (32). Notch1 is highly expressed in glioma cells and is closely associated with a tumor's pathological grade (33). GSI II effectively inhibits Notch1 signal activation (34). In the present study, GSI II was demonstrated to effectively inhibit TSC generation in U87 cells $(\mathrm{P}<0.05)$; additionally, a recent study demonstrated that the resistance of TSCs towards the tumor necrosis factor related apoptosis-inducing ligand could be induced, and its activation may increase the effects of chemotherapeutic drugs (35).

Although a previous study demonstrated that the U87 cell line is not authentic to the tumor of the original cell established in the University of Uppsala in 1968, it is also a glioblastoma cell line (36). The purpose of the present study was to isolate and cultivate TSCs, and examine the effect of GSI II on the growth and differentiation of TSCs. Therefore, the U87 cell line from ATCC or the U87 cell line from Uppsala University could be used in the present study and without affecting the results.

The present study provides a foundation for developing therapeutics for the treatment of glioma. The selective killing of TSCs in brain tumors may prevent tumor recurrence and metastasis, providing a means for curing or preventing tumor recurrence and metastasis.

\section{Acknowledgements}

Not applicable.

\section{Funding}

This study was funded by Shandong Provincial Natural Science Foundation (grant no. ZR2012HM084).

\section{Availability of data and materials}

All data generated or analyzed during this study are included in this published article.

\section{Authors' contributions}

XDD and CQD conceived and designed the study. XDD, CQD, FW, WSD, MMY, QHM and PS performed the experiments. XDD and MMY conducted the statistical analysis. XDD and CQD wrote the paper. PS reviewed and edited the manuscript. All authors read and approved the manuscript. 


\section{Ethics approval and consent to participate}

Not applicable.

\section{Patient consent for publication}

Not applicable.

\section{Competing interests}

The authors declare that they have no competing interests.

\section{References}

1. Lowenstein PR and Castro MG: Evolutionary basis of a new gene- and immune-therapeutic approach for the treatment of malignant brain tumors: From mice to clinical trials for glioma patients. Clin Immunol 189: 43-51, 2018.

2. Baker GJ, Yadav VN, Motsch S, Koschmann C, Calinescu AA, Mineharu Y, Camelo-Piragua SI, Orringer D, Bannykh S, Nichols WS, et al: Mechanisms of glioma formation: Iterative perivascular glioma growth and invasion leads to tumor progression, VEGF-independent vascularization, and resistance to antiangiogenic therapy. Neoplasia 16: 543-561, 2014.

3. Nakano I and Kornblum HI: Methods for analysis of brain tumor stem cell and neural stem cell self-renewal. Methods Mol Biol 568: 37-56, 2009.

4. Turner JD and Sanai N: A brain tumor stem cell origin for glioblastoma endothelium. World Neurosurg 75: 574-575, 2011.

5. Khan IS and Ehtesham M: Isolation and characterization of stem cells from human central nervous system malignancies. Adv Exp Med Biol 853: 33-47, 2015.

6. Bryukhovetskiy A, Shevchenko V, Kovalev S, Chekhonin V Baklaushev V, Bryukhovetskiy I and Zhukova M: To the novel paradigm of proteome-based cell therapy of tumors: Through comparative proteome mapping of tumor stem cells and tissue-specific stem cells of humans. Cell Transplant 23 (Suppl 1): S151-S170, 2014

7. Toda M: Identification of antigen against brain tumor stem cell and application for treatment of glioma. Gan To Kagaku Ryoho 37: 1016-1018, 2010 (In Japanese).

8. Tanaka S, Louis DN, Curry WT, Batchelor TT and Dietrich J: Diagnostic and therapeutic avenues for glioblastoma: No longer a dead end? Nat Rev Clin Oncol 10: 14-26, 2013.

9. Lathia JD, Li M, Hall PE, Gallagher J, Hale JS, Wu Q, Venere M, Levy E, Rani MR, Huang P, et al: Laminin alpha 2 enables glioblastoma stem cell growth. Ann Neurol 72: 766-778, 2012.

10. Sherriff J, Tamangani J, Senthil L, Cruickshank G, Spooner D, Jones B, Brookes C and Sanghera P: Patterns of relapse in glioblastoma multiforme following concomitant chemoradiotherapy with temozolomide. Br J Radiol 86: 20120414, 2013.

11. Neradil J and Veselska R: Nestin as a marker of cancer stem cells. Cancer Sci 106: 803-811, 2015.

12. Tampaki EC, Nakopoulou L, Tampakis A, Kontzoglou K, Weber WP and Kouraklis G: Nestin involvement in tissue injury and cancer-a potential tumor marker? Cell Oncol (Dordr) 37 305-315, 2014

13. Yiming L, Yunshan G, Bo M, Yu Z, Tao W, Gengfang L Dexian F, Shiqian C, Jianli J, Juan T and Zhinan C: CD133 overexpression correlates with clinicopathological features of gastric cancer patients and its impact on survival: A systematic review and meta-analysis. Oncotarget 6: 42019-42027, 2015.

14. Kemper K, Grandela C and Medema JP: Molecular identification and targeting of colorectal cancer stem cells. Oncotarget 1 : 387-395, 2010.

15. Garcia A and Kandel JJ: Notch: A key regulator of tumor angiogenesis and metastasis. Histol Histopathol 27: 151-156, 2012.

16. Ye L, Wang C, Yu G, Jiang Y, Sun D, Zhang Z, Yu X, Li X, Wei W, Liu $\mathrm{P}$, et al: Bmi-1 induces radioresistance by suppressing senescence in human U87 glioma cells. Oncol Lett 8: 2601-2606, 2014.

17. Wilson NH and Stoeckli ET: Sonic Hedgehog regulates Wnt activity during neural circuit formation. Vitam Horm 88: 173-209, 2012.
18. Foldynová-Trantírková S, Sekyrová P, Tmejová K, Brumovská E, Bernatík O, Blankenfeldt W, Krejcí P, Kozubík A, Dolezal T, Trantírek L and Bryja V: Breast cancer-specific mutations in CK1epsilon inhibit Wnt/beta-catenin and activate the Wnt/Rac1/JNK and NFAT pathways to decrease cell adhesion and promote cell migration. Breast Cancer Res 12: R30, 2010.

19. Izraeli S, Lowe LA, Bertness VL, Campaner S, Hahn H, Kirsch IR and Kuehn MR: Genetic evidence that Sil is required for the Sonic Hedgehog response pathway. Genesis 31: 72-77, 2001.

20. Jin X, Jeon HM, Jin X, Kim EJ, Yin J, Jeon HY, Sohn YW, Oh SY, Kim JK, Kim SH, et al: The ID1-CULLIN3 axis regulates intracellular SHH and WNT signaling in glioblastoma stem cells. Cell Rep 16: 1629-1641, 2016.

21. Filbin MG, Dabral SK, Pazyra-Murphy MF, Ramkissoon S, Kung AL, Pak E, Chung J, Theisen MA, Sun Y, Franchetti Y, et al: Coordinate activation of $\mathrm{Shh}$ and PI3K signaling in PTEN-deficient glioblastoma: New therapeutic opportunities. Nat Med 19: 1518-1523, 2013.

22. Zhou QZ, Zhang G, Long HB, Lei F, Ye F, Jia XF, Zhou YL, Kang JP and Feng DX: Effect of spinal cord extracts after spinal cord injury on proliferation of rat embryonic neural stem cells and Notch signal pathway in vitro. Asian Pac J Trop Med 7: 562-567, 2014.

23. Chen CY, Liao W, Lou YL, Li Q, Hu B, Wang Y and Deng ZF: Inhibition of Notch signaling facilitates the differentiation of human-induced pluripotent stem cells into neural stem cells. Mol Cell Biochem 395: 291-298, 2014.

24. Saito N, Fu J, Zheng S, Yao J, Wang S, Liu DD, Yuan Y, Sulman EP, Lang FF, Colman H, et al: A high Notch pathway activation predicts response to $\gamma$ secretase inhibitors in proneural subtype of glioma tumor-initiating cells. Stem Cells 32: 301-312, 2014.

25. Glass R and Synowitz M: CNS macrophages and peripheral myeloid cells in brain tumours. Acta Neuropathol 128: 347-362, 2014.

26. $\mathrm{Hu}$ M, Xiang FX and He YF: Are cancer stem cells the sole source of tumor? J Huazhong Univ Sci Technolog Med Sci 34: 621-625, 2014.

27. Alamgeer M, Peacock CD, Matsui W, Ganju V and Watkins DN: Cancer stem cells in lung cancer: Evidence and controversies. Respirology 18: 757-764, 2013.

28. Fong D, Yeh A, Naftalovich R, Choi TH and Chan MM: Curcumin inhibits the side population (SP) phenotype of the rat C6 glioma cell line: Towards targeting of cancer stem cells with phytochemicals. Cancer Lett 293: 65-72, 2010.

29. Lucarelli G, Galleggiante V, Rutigliano M, Vavallo A, Ditonno P and Battaglia M: Isolation and characterization of cancer stem cells in renal cell carcinoma. Urologia 82: 46-53, 2015.

30. Lehnus KS, Donovan LK, Huang X, Zhao N, Warr TJ, Pilkington GJ and An Q: CD133 glycosylation is enhanced by hypoxia in cultured glioma stem cells. Int J Oncol 42: 1011-1017, 2013.

31. Brazel CY, Alaythan AA, Felling RJ, Calderon F and Levison SW: Molecular features of neural stem cells enable their enrichment using pharmacological inhibitors of survival-promoting kinases. J Neurochem 128: 376-390, 2014.

32. Tamura K, Aoyagi M, Ando N, Ogishima T, Wakimoto H, Yamamoto $\mathrm{M}$ and Ohno K: Expansion of CD133-positive glioma cells in recurrent de novo glioblastomas after radiotherapy and chemotherapy. J Neurosurg 119: 1145-1155, 2013

33. Fang KM, Lin TC, Chan TC, Ma SZ, Tzou BC, Chang WR, Liu JJ, Chiou SH, Yang CS and Tzeng SF: Enhanced cell growth and tumorigenicity of rat glioma cells by stable expression of human CD133 through multiple molecular actions. Glia 61: 1402-1417, 2013.

34. Kim SH and Singh SV: Mammary cancer chemoprevention by withaferin $\mathrm{A}$ is accompanied by in vivo suppression of self-renewal of cancer stem cells. Cancer Prev Res (Phila) 7 : 738-747, 2014.

35. Zhang X, Chen T, Zhang J, Mao Q, Li S, Xiong W, Qiu Y, Xie Q and Ge J: Notch1 promotes glioma cell migration and invasion by stimulating $\beta$-catenin and NF- $\kappa \mathrm{B}$ signaling via AKT activation. Cancer Sci 103: 181-190, 2012.

36. Xiao YG, Wang W, Gong D and Mao ZF: $\gamma$-Secretase inhibitor DAPT attenuates intimal hyperplasia of vein grafts by inhibition of Notch1 signaling. Lab Invest 94: 654-662, 2014. 